\title{
JURISPRUDENCIA SOBRE RESPONSABILIDAD PATRIMONIAL EXTRACONTRACTUAL POR MAL FUNCIONAMIENTO DEL SISTEMA SANITARIO
}

\author{
Carlos BODAs RodRíguez \\ Departamento de Derecho Administrativo \\ Facultad de Derecho. \\ Universidad Complutense de Madrid \\ cbodas01@ucm.es
}

I. SENTENCIA DEL TRIBUNAL SUPREMO, SALA DE LO CONTENCIOSO-ADMINISTRATIVO, SECCIÓN 4. ${ }^{a}$, NÚM. 207/2017, DE 8 DE FEBRERO (RJ 2017/1033)

Los recurrentes interpusieron recurso contencioso-administrativo ante el Tribunal Superior de Justicia (en adelante, TSJ) de la Comunidad Valenciana contra la resolución del conseller de Sanidad desestimatoria de la reclamación por responsabilidad patrimonial de la Administración por la asistencia sanitaria prestada a Josefa por no habérsele detectado el hipotiroidismo durante el embarazo de su madre, recurso que se desestimó, interponiéndose después un nuevo recurso de casación del que se acaba declarando no haber lugar.

La desestimación del recurso se fundamenta en que se ha rebasado el plazo de un año para reclamar por responsabilidad patrimonial. En relación al fondo, por qué no se detectó el hipotiroidismo vendría dado por el hecho - que explica la especialista — de que no siendo congénito, sino producido por las propias malformaciones cerebrales de la niña, es lógico que no se detectara hasta con posterioridad a su nacimiento, factor al que deben unirse los límites del estado de la ciencia en 2001 frente al diagnóstico de la malformación cerebral; síndrome que, a juicio de los antedichos especialistas, explicaba la totalidad de los síntomas padecidos por la menor, al margen del hipotiroidismo padecido. Consecuentemente, y a falta de aportación por los recurrentes de un perito con especialidad más cualificada y adecuada, debe concluirse que no aparece acreditada la 
infracción de la lex artis en la asistencia sanitaria prestada a Josefa, lo que determina la desestimación del recurso desde la óptica de los argumentos de fondo. En cuanto a la prescripción, que ya bastaría para la desestimación del recurso, lo relevante es fijar el momento en que se determina el alcance de las secuelas. El hipotiroidismo se diagnostica junto al resto de las secuelas que padece la menor tras realizar una resonancia nuclear magnética y otras pruebas, cuando la menor tenía más de dos años de edad (en 2004 y la reclamación ante la Consellería de Sanidad se produce en 2008), y es a partir de ese momento cuando queda determinado el alcance de dichas secuelas. Cuestión distinta es que al ser daños permanentes, no reversibles, estos no sean curables y permanezcan durante la vida de la niña, pero ello no determina que puedan reclamarse mientras persistan. El plazo debe computarse, ese es el dies a quo, desde que se conocen los efectos definitivos del daño. La declaración de incapacidad posterior años más tarde es una decisión administrativa llamada a desplegar su eficacia principalmente en el ámbito laboral y de previsión social, y presupone una previa verificación de todas las consecuencias del accidente, pero ha de estarse como dies a quo el momento en que se determina el alcance de las secuelas.

\section{SENTENCIA DEL TRIBUNAL SUPREMO, SALA DE LO CONTENCIOSO-ADMINISTRATIVO, SECCIÓN 4. ${ }^{a}$, DE 9 DE FEBRERO DE 2016 (RJ 2016/1632)}

El TS desestima el recurso de casación interpuesto por don Cosme contra la sentencia del TSJ de la Comunidad Valenciana. El TS no entra a valorar si concurren los requisitos legalmente exigibles para que prospere una pretensión indemnizatoria ni aborda la pretendida incongruencia de la sentencia impugnada. Entra fundamentalmente a valorar si la reclamación de responsabilidad patrimonial de la Administración fue efectivamente presentada fuera de plazo. El recurrente, tras sufrir una caída el 3 de febrero de 2008 en Vinaròs, acudió al hospital de esa población, siendo diagnosticado de «fractura de maleolo de peroné derecho sin desplazamiento». Solicitó posteriormente cita en el hospital de Alcañiz, donde tiene su domicilio, acudiendo el 14 de marzo de 2008 a traumatología; a partir de esa fecha se suceden actuaciones de la sanidad pública aragonesa, que culminan con una intervención quirúrgica el 2 de marzo de 2009 y cita con el especialista, quien emite su informe el 3 de julio; emitiéndose por último el 24 de julio de 2009 Dictamen del EVI con calificación de incapacidad permanente en 
grado total. El actor formula su reclamación ante la Administración el día 8 de julio de 2010.

El TS afirma que, en la hipótesis más favorable al recurrente, en el informe médico del 3 de julio de 2009 quedan definitivamente reflejadas las secuelas de la fractura sufrida, sin que conste ningún tratamiento posterior. El recurrente sostiene, por el contrario, que como dies a quo debe considerarse el 24 de julio de 2009, fecha en que el órgano administrativo correspondiente hizo la declaración de incapacidad permanente para el trabajo. Pero la verdad es que no consta que entre esas dos fechas hubiera ninguna evolución de las secuelas ni que se produjera un cambio significativo de los daños sufridos. La declaración de incapacidad permanente es una decisión administrativa llamada a desplegar su eficacia principalmente en el ámbito laboral y de previsión social y presupone una previa verificación de todas las consecuencias del accidente. Tanto el informe médico como la decisión administrativa presuponen que las secuelas habían quedado definitivamente fijadas con anterioridad, por lo que la apreciación de la prescripción hecha por la sentencia impugnada es ajustada a Derecho.

\section{SENTENCIA DEL TRIBUAL SUPREMO, SALA DE LO CONTENCIOSO-ADMINISTRATIVO, SECCIÓN 4. ${ }^{a}$, DE 9 DE OCTUBRE DE 2015 (RJ 2015/4857)}

El 30 de noviembre de 2008 don Balbino comenzó a tener fiebre alta y el 1 de diciembre acudió a la consulta de la médico de familia. Se le diagnosticó una infección urinaria. El 2 de diciembre continuó con fiebre y el 3 de diciembre la familia llamó al centro de salud. La médico le indicó que la medicación tardaría un poco en hacer efecto. Como el paciente empeoraba llamaron de nuevo, acudiendo una médico que, tras explorarle, solicitó una ambulancia y lo envió al hospital. En urgencias es diagnosticado de meningitis bacteriana e ingresado en la Unidad de Cuidados Intensivos. Fue dado de alta el 29 de diciembre y en el informe se describen como secuelas una hipoacusia importante. El 1 de abril de 2009 sufrió una parada cardiorespiratoria isquémica y encefalopatía postanóxica.

El recurso de casación se basa en la errónea valoración de la prueba practicada en la instancia, pero el TS no puede entrar ni en la apreciación de los hechos debatidos ni en la valoración de la prueba practicada; se ciñe a juzgar si el tribunal de instancia ha infringido las normas de valoración de una prueba. La pericial es una prueba de libre valoración con 
arreglo a la sana crítica y solo habrá infracción legal si la prueba no se ha valorado o, más que «sana critica», ha habido una valoración que encierra auténtica irracionalidad o carencia absoluta de sustento de la decisión o conduce a resultados inverosímiles, lo que no es el caso. Centrándose el litigio en la regularidad de la atención prestada por la médico de familia, el hecho objeto de prueba se ciñó a si en esa visita infringió las reglas de la lex artis al no diagnosticar o sospechar un posible proceso meníngeo a la vista de la sintomatología y si hubo un funcionamiento anormal del servicio cuando al día siguiente se limitó a atenderle telefónicamente y solo fue derivado al hospital cuando, ya personado en su domicilio, otra médico advirtió su gravedad. El TS concluye que del juicio lógico valorativo de la Sala de instancia no cabe deducir - ni la recurrente lo razonaque esa valoración fuese ilógica, aberrante o irracional, ajena a las reglas de la sana crítica, ni respecto de cada una de las pruebas ni de la valoración conjunta de las mismas, desestimando, por tanto, el recurso. Plantear el pretendido error en el juicio diagnóstico llevaría al TS a entrar a valorar de nuevo las pruebas practicadas y no a juzgar la sentencia, que es el objeto del recurso.

\section{SENTENCIA DEL TRIBUNAL SUPREMO,} SALA DE LO CONTENCIOSO-ADMINISTRATIVO, SECCIÓN 6. , DE 25 DE SEPTIEMBRE DE 2015 (RJ 2015/4214)

Don Argimiro interpone recurso de casación contra sentencia de la Audiencia Nacional que desestima el recurso interpuesto contra resolución del Ministerio del Interior en la que se le concede una indemnización de 180.000 euros por «pérdida de oportunidad» como consecuencia del retraso de la Administración penitenciaria en trasladarle desde el centro penitenciario en el que estaba hasta el hospital después de que sufriera un ictus ACM (embolia o trombosis), habiendo resultado con hemiplejia en la mitad izquierda del cuerpo, pérdida del habla y multitud de secuelas que le habrían supuesto una disminución del 80 por 100. La Administración acepta su responsabilidad patrimonial y cuantifica los daños que se le ocasionaron en 536.380,68 euros (por aplicación de las tablas III y IV del Anexo del Real Decreto Legislativo 8/2004, de 29 de octubre, mientras la parte actora aplica la tabla VI elevando la cantidad de la indemnización al doble), señalando que lo indemnizable es la pérdida de una oportunidad, por lo que cuantifica la indemnización por esta en la tercera parte 
de la valoración de las secuelas (180.000 euros), entendiendo adecuada la reducción de la indemnización en $2 / 3$ que se corresponde con el porcentaje de éxito del tratamiento señalado por los peritos.

El recurrente en casación alega falta de motivación en la sentencia de instancia y entiende que se hace una doble e indebida acumulación de reducciones de la indemnización. El TS desestima ambos al considerar que el Tribunal a quo motiva en forma las razones por las que asume la tesis de la Administración, de tal forma que, partiendo del carácter orientativo del baremo, considera procedente acudir a las tablas III y IV del Anexo, rechazando la posición de la parte actora de tener que acudir a la tabla IV. Igual suerte desestimatoria corre el segundo, en el que de facto se está impugnando el quantum indemnizatorio, cuyo alcance de forma motivada, razonable y ponderada efectúa la sentencia, dando cumplimiento a la necesidad de la plena indemnidad o reparación integral de los daños causados. El concepto por el que se indemniza es uno solo, el de la pérdida de oportunidad de haber evitado las secuelas si el traslado al hospital hubiera sido más rápido, y es a los exclusivos efectos de la indemnización de ese concepto para lo que se opera determinando con carácter previo el alcance de las secuelas, sin que haya una disminución de estas al hacer su valoración.

\section{SENTENCIA DEL TRIBUNAL SUPREMO, SALA DE LO CONTENCIOSO-ADMINISTRATIVO, SECCIÓN 4. ${ }^{a}$, DE 6 DE MAYO DE 2015 (RJ 2015/3078)}

El TS estima en parte el recurso contencioso-administrativo interpuesto contra la desestimación de la reclamación de responsabilidad patrimonial presentada el 28 de diciembre de 2006 por la asistencia sanitaria recibida por doña Concepción en el hospital 12 de octubre de Madrid durante el parto de su hijo Dimas, nacido en 1988, como consecuencia de la cual se habrían producido las secuelas constatadas por la Consejería de Sanidad el 16 de octubre de 2006, por la que se le reconoce un grado de minusvalía del 68 por 100. El TSJ de la Comunidad de Madrid entendió que la reclamación tuvo lugar fuera del plazo de prescripción de un año previsto, toda vez que las secuelas padecidas por Dimas ya estaban perfectamente determinadas en 1990, decisión a la que se opone la parte recurrente por cuanto, a su juicio, si bien la secuela neurológica tiene su origen en el parto, la determinación de su concreto alcance solo ha sido posible tras la consta- 
tación (el 10 de junio) de un retraso mental «moderado», cualitativamente superior al retraso «leve» que aparecía en 1990.

El TS entiende que dichas secuelas se debieron a la asistencia médica durante el parto, infringiéndose la lex artis, asentándose en: a) la imposibilidad de afirmar, con absoluta certeza, que en la asistencia al parto no existió sufrimiento fetal; $b$ ) la ausencia, por extravío, de los documentos esenciales en los que se contienen los datos y gráficas que recogen la forma en que tuvo lugar la asistencia en las horas anteriores a la cesárea, documentos que la Administración no custodió debidamente y que no han podido ser tenidos en cuenta por la parte actora para defender su pretensión resarcitoria; c) la improcedencia de hacer recaer sobre quien defiende la existencia de sufrimiento fetal las consecuencias derivadas de la falta de una documentación que la demandada tenía la obligación de conservar y aportar y que resultaba determinante para precisar la forma en que la asistencia fue prestada. El TS determina la cuantía de la indemnización en 110.000 euros más intereses legales, a la que el afectado tiene derecho por la única secuela que puede tenerse en cuenta en tanto que probada (el retraso mental moderado), teniendo en cuenta a efectos orientativos las disposiciones contenidas en los Anexos del Real Decreto Legislativo $8 / 2004$, de 29 de octubre. 